\title{
Buddhist Perspective for Organization Human Resource Development: Reference to the Maha Mangala Sutta
}

\author{
Padmasiri M.KD \\ Department of Human Resource Management, Faculty of Commerce and Management Studies, University of Kelaniya, Sri Lanka
}

Copyright $\mathrm{C} 2016$ by authors, all rights reserved. Authors agree that this article remains permanently open access under the terms of the Creative Commons Attribution License 4.0 International License

\begin{abstract}
Human Resource Development (HRD) is playing a major role in today's business world to enhance HR skills, attitudes and knowledge. HRD can be defined as a set of systematic \& planned activities designed by an organization to provide its member with opportunities to learn necessary skills to meet current \& future job demands. HRD scope has built on four major functions including career development, individual development, performance management and organizational development. Purpose of this study was to find how can be applied principles in Mahamangala Sutta to the sub components of Individual Development (ID): development of skills, knowledge and behavior in order to achieve objectives of organizational HRD. Past studies did not sufficiently explain religious perspective related to HRD discipline. Present study has involved to filling this gap by focusing on one of the most well-known suttas to explore its meanings with the scope of HRD. Researcher depended on Thripitaka (contains three "baskets" of teachings: a: Sutta Pitaka (pyxidium), Vinaya Pițaka and an Abhidharma Pițaka) and other Buddhism books. Mahamangala sutta explained thirty eight principles for individual development and this study made a bridge between Buddhism and ID by identifying how those principles categories under sub component in ID at the organization level. Application of these principles in this selected sutta will create sound outcomes to the organization where recommendations supposed to apply innovative practices in order to achieve organizations success.
\end{abstract}

Keywords HRD, Mahamangala Sutta, Individual Development, Skills, Knowledge, Behavior

\section{Introduction}

HR is source of competitive advantage and not merely employees fulfilling their job responsibilities in but to perform efficiently and effectively. To perform expected level employees must possess with required level of knowledge and skills. The field of Human Resource
Development (HRD) encompasses several aspects of enabling and empowering $\mathrm{HR}$ in organization. Current paradigm in HRD treats employees as value creators and assets Heathfield [1]. HRD is the framework for helping employees develops their personal and organizational skills, and knowledge McLagan [2]. HRD includes such opportunities as employee training and development, career development, performance management and individual development, in order to gain organization development. The focus of all aspects in HRD is developing the most superior workforce and it ultimately organization able to accomplish its vision statement. HRD is set of planned and systematic activities designed by an organization to provide opportunities to its members to learn skills necessary for the present and future job requirements. HRD involves the development of expertise in the employee through organizational development and training and development. The aim of HRD is to improve the performance of the employees Robert [3]. Scope of the HRD has extended over four main criteria including; Individual Development (ID), Career Management, Organizational Development and Performance Management Gilley et al [4].

In the world scenario could able to identify different religious perspectives including few dominant religions such as Christianity, Buddhism, Catholic, Hinduism, and Muslim. Among those dominant religion present study scope is limited to Buddhism perspective which founded by Gautama Buddha, also known as Siddhārtha Gautama, Shakyamuni, or simply the Buddha. Lord Buddha is a primary figure in Buddhism and discoursed sermons in different aspects which spread over various disciplines Kalupahana [5]. For this study researcher occupied Mahamangala Sutta which is one of the suttas among suttas like Karaniya Metta Sutta and Vyagghapajja Sutta which were preached for ID and current study has selected Mahamangala Sutta preached by him.

\section{Significance of the Study}

How does Buddhism contribute to understanding of Human Resource Development (HRD) has clearly explained by Siriporn [6] and academic knowledge regarding Buddhist perspective and HR practices are less. Therefore current 
study filled that gap through linking Buddhism and HRD. Further, this attempt is not to extend any religion but to gathering practicality of Buddhism in developing HRD at organizational level. With that primary purpose present study researcher investigated about how Buddhism can be used to develop a model for HRD in ID aspect.

\section{Maha Mangala Sutta}

According to Thripitaka [7] a discourse known as Mangala Sutta, including (38) thirty-eight highest blessings which was elaborated how would be a human can gain personal attainment. Besides, these thirty-eight blessings are ethical and spiritual in nature, providing a step-by-step training on the journey of individual's life. The researcher first attempt was elaborate the meaning of thirty eight blessings based on English translation developed by Soni's [8] Life Highest Blessing commentary.

Table 1. English Translation of 38 blessings

\begin{tabular}{|c|c|c|}
\hline No & Pali text & English translation \\
\hline 1 & Anaakulaa ca kammantaa: & Business pursuits, peaceful and free from conflicts \\
\hline 2 & Daana & Acts of giving \\
\hline 3 & Dhammacariyaa & Conduct according to Dhamma \\
\hline 4 & Naatakaana $\sim$ ca sa"ngaho & Helping one's relatives \\
\hline 5 & Anavajjaani kammaani & Blameless actions \\
\hline 6 & Aarati paapaa & shunning evil \\
\hline 7 & Virati paapaa & Abstaining from evil \\
\hline 8 & Majjapaanaa ca sa $\sim$ n namo & Refraining from intoxicants \\
\hline 9 & Appamaado ca dhammesu & Diligence in practice of what is Dhamma \\
\hline 10 & Gaaravo & Reverence \\
\hline 11 & Nivaato & Humility \\
\hline 12 & Santu.t.thi & Contentment \\
\hline 13 & Kata $\sim$ n nutaa & Gratefulness \\
\hline 14 & Kaalena dhammasavana & Timely hearing of the Dhamma \\
\hline 15 & Khanti & Patience \\
\hline 16 & Sovacassataa & Meekness when corrected \\
\hline 17 & Asevanaa ca baalaanam & Not associating with fools \\
\hline 18 & Pan.ditaana $\sim \mathrm{n}$ ca seyanaa & Associating with the wise \\
\hline 19 & Puujaa ca puujaniiyaanam & Reverencing those worthy of respect \\
\hline 20 & Patiruupadesavaaso & Residence in a suitable locality \\
\hline 21 & Pubbe ca katapu $\sim \mathrm{n} \sim$ nataa & Having made merit in the past \\
\hline 22 & Attasammaapa.nidhi & One's mind properly directed \\
\hline 23 & Bahusacca $\sim$ n & Profound learning \\
\hline 24 & Bahusippa $\sim \mathrm{n}$ & Proficiency in one's work \\
\hline 25 & Vinayo ca susikkhito & Well-learned moral discipline \\
\hline 26 & Subhaasitaa ca yaa vaacaa & Gracious kindly speech \\
\hline 27 & Maataa pitu upa.t.thaana.m & Giving support to parents \\
\hline 28 & Puttadaarassa sa"ngaho & Cherishing wife and children \\
\hline 29 & Sama.naana $\sim$ ca dassanam & Meeting (seeing) monks \\
\hline 30 & Kaalena dhammasaakacchaa & Discussing the Dhamma at the proper time \\
\hline 31 & Tapo & Energetic self-restraint \\
\hline 32 & Brahmacariyaa & Holy and chaste life \\
\hline 33 & Ariyasaccaana dassanam & Insight into the Noble Truths \\
\hline 34 & Nibbaana sacchikiriyaa & Realization of Nibbaana \\
\hline 35 & Phu.t.thassa lokadhammehi citta.m yassa na kampati & A mind unshaken by the ups and downs of life \\
\hline 36 & Asokam & Freedom from sorrow \\
\hline 37 & Virajam & Freedom from defilements of passion \\
\hline 38 & Khemam & Perfect security \\
\hline
\end{tabular}


According to the Sutta thirty two (32) principles (one thirty two) for mundane development and others (thirty three- thirty eight) for super-mundane development. Therefore researcher scope limited to first thirty two principles and among those principles identified which will be related to ID at the organization level.

\section{Individual Development and Maha Mangala Sutta}

Through the study identified principles of selected sutta which are highly committed to ID; the selected sub component of the scope of HRD. According to Eggland [8] ID refers to the development of new knowledge, skills, and/or improved behaviors that result in performance enhancement and improvement related to one's current job (training). ID refers to the development of new knowledge, skills, and/or improved behaviors that result in performance enhancement and improvement related to one's current job (training) Eggland [8]. This study has focused on the ID at the organization context.

As demonstrated by Eggland [8] major components of ID are development of new knowledge, skills and improvement of behavior. Initially researcher identified three factors of ID then identified principles which are relevant to each factor. Accordingly, identified not associating with fools, associating with the wise and one's mind properly directed supposed to develop employee skills and knowledge under ID. Meanwhile including above three principles and reverencing those worthy of respect, gracious kindly speech, acts of giving, refraining from intoxicants, humility, contentment, gratefulness, patience and meekness when corrected are characterized below improvement of behavior in ID. In conclusion researcher identified twelve (12) principles among first thirty two principles in Sutta to categorize under sub variables of ID as follow.

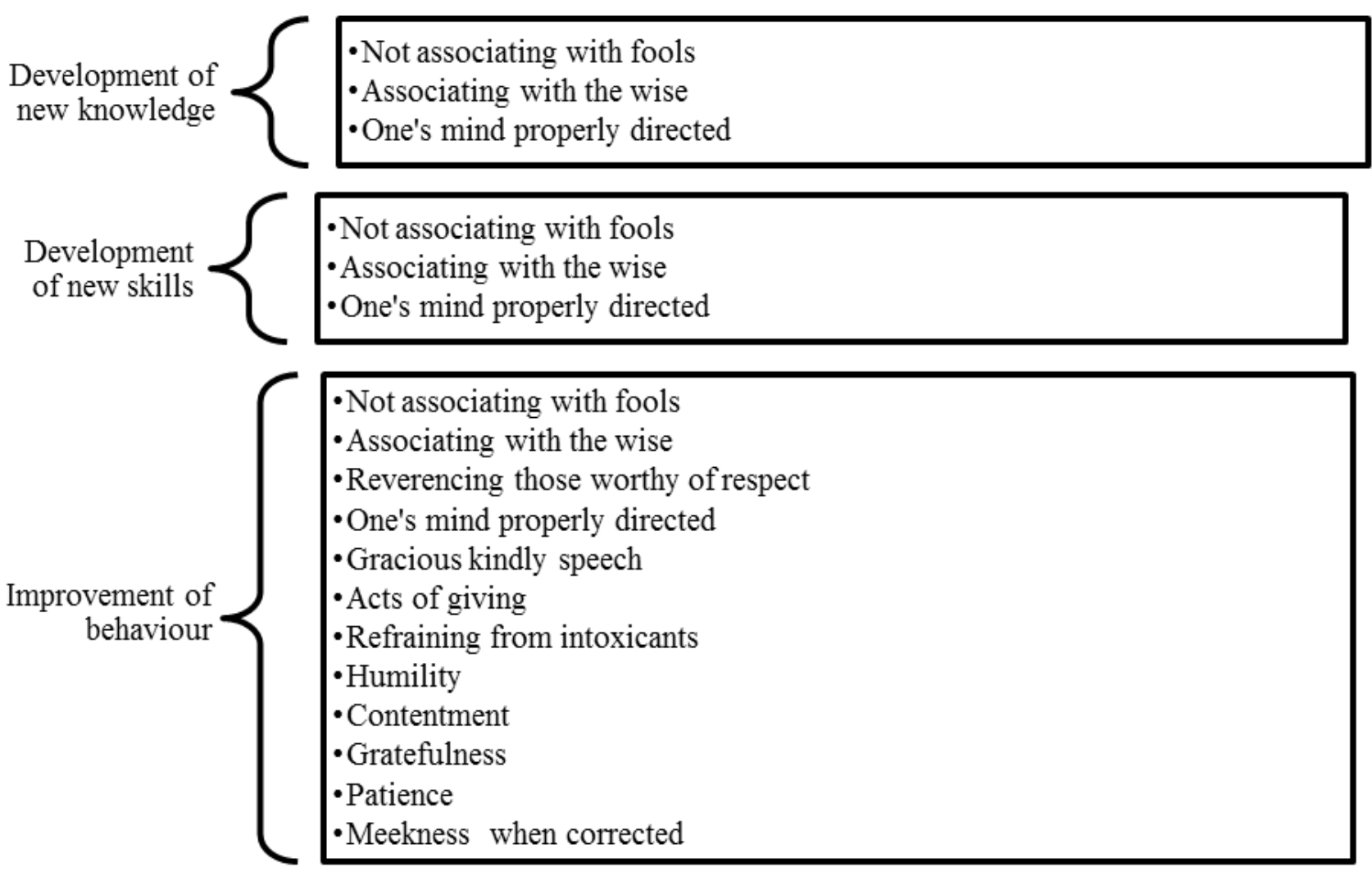

Figure 1. Individual Development with Maha Mangala Sutta 
Not associating with fools: According to the figure 1 findings development of new knowledge, skills and behavior is influenced by this principle. When the person is not having relationship with foolish people that person able to enhance his knowledge, skills and behavior is describing by this argument. According to Soni [9] this principle emphasis is on keeping away from and not getting entangled with people who, though grown up in years, have none of the graces of children but all their failings and shortcomings; these are the people possessing the characteristics of "fools." It reveals that when a person accompany with another who represents above characteristics will make different disadvantages at organization level as for example they might direct people to engage non accepted behaviour. It can be concluded that Development of knowledge, skills and behavior under ID is depending on this association. Therefore employee should associate with people who are not displaying such negative appearances in order to overcome negative outcomes.

Associating with the wise: Opposite of the above principle is associating with wise, sequence of companionship with the wise is: listening to good advice, rational faith, noble thoughts, clear thinking, self-control, good conduct, conquest of the hindrances, gaining of wisdom and the consequent liberation. Once who is advanced in self-control, full of loving-kindness and compassion and thus immune to the evils of such association Soni [9]. Further showed that wise association makes wise people therefore to develop knowledge, skills and behaviour employees should maintain relationship with wise.

One's mind properly directed: Action is performed by one's body or by speech or by mind and these actions are directed by own mind. If there were no "will" in mind to involved, there would be no results. According to Buddha the emphasis is on "one's own self": one should try to direct oneself to the desired goal by the efforts one makes. This encourages self-confidence and discourages dependence upon the grace of men. It says many people pass their lives in the wrong course, engaged in evil practices of the body (behavior), speech and mind was a result of absent of properly directed mind. In that logic when person's mind correctly directed, it will be supposed to obtain skills, knowledge and behavior which are the main requirement of ID.

Reverencing those worthy of respect: In understating reverence under business perspective it could be defined as respect to each other. In business perspective this principle is essential fact to maintain sound relationship. In the case of development of behaviour under ID it is required to encourage this positive behaviour in order to promote appreciable culture within the organization.

Gracious kindly speech: Well-spoken words of civility make harmonious environment hence, certainly what one speaks and how one speaks it and considering all the words which pour out of our mouths every day is very important Soni [9].Words can never be ill-spoken words since they are: true; bring concord; are compassionate; and meaningful. According to Catania [10] behavior would be verbal or nonverbal. This practice bond with development of behavior because speech is a verbal behavior and once who speak positively will be displayed positive behaviour. Ultimately this practice would lead ID and in order to enhance HRD.

Acts of giving: When a person practice to giving behaviour it is a kind of positive behavior because according to Buddhism giving is related to moral conduct. In business perspective giving nature is required, when employees are having such behaviour it leads to development of positive behavior, therefore it can be concluded that this principle leads to achieve ID.

Refraining from intoxicants: Playing on intoxication and maddening leads to destroy of the mind therefore people should maintain a clear mind and body and it will be a major issue at organization when employee is having intoxication while working. General norm is intoxicants finish the positive behavior of person. Any employee must ensure that he or she is not under the influence of an intoxicant where the extent of the intoxicants could endanger his or her own safety, health or welfare at work or that of any other person present Health and Safety Authority [11]. Therefore referencing from intoxicant leads to improve one's own behavior and finally at organization level could achieve ID.

Humility: This is a factor which stresses the importance of absence of pride. According to Soni [9] this does not mean that one is obsequiously "humble"- just another disguise for pride. Further revealed humble person does not advertise himself; not exuberant in body or speech but instead is restrained. As a result of being humble to everyone at the work environment is kind of behavioral development because according to Catania [10] behavior consist with two as verbal and nonverbal and being humility is related to nonverbal behavior. As the result of behaviour development organization will able to gain ID under HRD.

Contentment: This implies acceptance of conditions and situations as they arise, with equanimity and without grumbling. This is a positive value which should be improve by people under behavior. Buddhism discoursed one can be content with enough clothes, enough food, enough living room and enough medicines. "Enough" gives one little trouble to keep and maintain but more than that brings anxiety and worry therefore everyone has to decide for themselves whether get more happiness or more trouble. In business perspective employees should practice to be contentment and ultimately it makes the improvement of behavior in ID because Soni [9] said contentment is a part of sound behavior of a person.

Gratefulness: The Buddha preached: "Two sorts of people are hard to find in the world: one who first does (something kind or helpful), and one who is grateful and recognizes (that kindness)." Absence of gratefulness person will drive towards negative behaviour hence this principle represents the practice that should be used at the working environment because Soni [9] said grateful result to improve action (behavior) which is the sub component of ID.

Patience: This is important virtue, in fact one of the highest, and it includes the virtues of forbearance, 
forgiveness and tolerance. A person who practices patience will be created positive outcomes since Health and Safety Authority [11] presented that patience at the work place leads accident zero, and minimum conflicts. Patience is an action of people and when employee improves this action means improves his behavior below ID.

Meekness when corrected: The meaning given is "one who can easily be addressed, spoken to or advised" and it further means "a person who can be corrected." Also implied qualities of tolerance of criticism directed at oneself and courtesy and gratitude in accepting advice. A person who is meek use the chance to learn therefore this action display positive behavior. In business perspective when employees prefer to correct their faults by accepting those represents characteristic under ID.

\section{Management Implication}

This section will be disclosed how each selected components in sutta could be applied in management practices in order to gain ID with the ultimate purpose of HRD. Since researcher discussed how those principles are related to sub components of ID, supposed to clarify what type of management practices could be applied to enhance such principles at organization level in business perspective.

\section{Conclusions}

Intention of the researcher was find the relationship between ID with Buddhism which was the selected sub component of the scope of HRD. Primary objective of HRD is planned and designed activities at organization to provide its member with opportunities to learn necessary skills, knowledge and behavior to meet current \& future job demands. HRD encompasses with Career Development, Performance Management, Organization Development and Individual Development (ID).

In Buddhism Mahamangala Sutta was preached to ID of human in the society but present study found the relationship between principles discussed under that sutta and ID in HRD. Further, researcher clearly established how those selected principles link with the three sub components of ID including; development of skills, knowledge and behavior. And presented management practices related to each practice to illustrate how each principle can be developed within organization to obtain employees skills, knowledge and behavior development under ID component of HRD. Summary of the management practice can be illustrated as; create learning environment and hire who match with organizational culture, create clear communication flow, develop code of ethics, organize CSR activities with the support of employees, intoxicants should prohibit at the work environment, establish sound grievance handling procedure, proper induction programmes and organize moral and attitudes development programmes. In business viewpoint there is a facility to apply any religion perspectives by identify the link between those religious principles and management practices as which has done by present study. Current study remains with limitations including study investigated only one Sutta in Buddhism, among four components of HRD selected only ID, study is a concept paper hence cannot measure the findings, and study findings were depend on availability of literature.

Table 2. Management Practices

\begin{tabular}{|c|c|c|}
\hline No & Buddhist concept & Management practice \\
\hline 01 & Not associating with fools & $\begin{array}{l}\text { Create learning environment and hire who match with organizational culture. Then every employee has } \\
\text { opportunity to deal with nice people. }\end{array}$ \\
\hline 02 & Associating with the wise & $\begin{array}{l}\text { Create communication flow from senior to junior to transfer knowledge. Then every employee become } \\
\text { wise and they can associate each other. }\end{array}$ \\
\hline 03 & One's mind properly directed & $\begin{array}{c}\text { Develop code of ethics which should be followed by employee and organize positive thinking } \\
\text { programmes under training component. }\end{array}$ \\
\hline 04 & $\begin{array}{l}\text { Reverencing those worthy of } \\
\text { respect }\end{array}$ & $\begin{array}{l}\text { Develop the culture which lead employee respect each other and ethical qualities then will create sound } \\
\text { working environment with sound relationship. }\end{array}$ \\
\hline 05 & Gracious kindly speech & $\begin{array}{l}\text { Establish harmonious culture by aware employees about the importance of kind speech. Develop code of } \\
\text { ethics including this principle. }\end{array}$ \\
\hline 06 & Acts of giving & $\begin{array}{l}\text { Corporate Social Responsibility (CSR) programme is a kind of act of giving that the organization can do. } \\
\text { Then management can get the support of the organization employees to CSR works. Ultimately } \\
\text { employees also practice to giving. }\end{array}$ \\
\hline 07 & Refraining from intoxicants & $\begin{array}{l}\text { Alcohol and smoking should prohibit at the work environment and include it as a required compulsory } \\
\text { behavior of employees under disciplinary policy. }\end{array}$ \\
\hline 08 & Humility & $\begin{array}{l}\text { Maintain sound employee management relationship, and practice good grievance handling procedure } \\
\text { with respective on equal treat for everyone. }\end{array}$ \\
\hline 09 & Contentment & Practice employee to satisfy with existing resources through moral development programmes. \\
\hline 10 & Gratefulness & $\begin{array}{l}\text { At the induction demonstrate to new employees about the importance of being gratefulness to seniors at } \\
\text { the work place. }\end{array}$ \\
\hline 11 & Patience & Organize attitudes development programmes. \\
\hline 12 & Meekness when corrected. & Train employee to make their faults by organizing positive attitudes development programmes. \\
\hline
\end{tabular}




\section{Acknowledgements}

To make this great output regarding the Human Resource Development with respect to Buddhist philosophy Ven. Nawane Saddajiwa thero, Mr. H.M.D. Senarathna, Mrs. U.D. De Silava and Senior Lecturer Dr. D.U.Mohan gave their immeasurable support.

\section{REFERENCES}

[1] Heathfield, S. M. (2013, 05 31). Retrieved from About.com: $<$ http://www.mbaofficial.com/mba-courses/human-resourcemanagement/human-resource-planning-and-development/wh at-is-human-resource-development-and-what-are-the-functio ns-of-hrd/>

[2] McLagan, P. A. (1989). Systems Model 2000: Matching Systems Theory to Future HRD Issues. In D. B. Gradous, (Ed.) Systems Theory Applied to Human Resource Development. Alexandria,VA: ASTD Press. p. 61-90.

[3] H. Robert (2013). \& Quote; Development of human resources -- Part 1 Beyond Training a perspective on improving organizations and people in the paper industry.

[4] Gilley, J., Eggland, S., \& Maycunich, A. (2002: 14).
Principles of Human Resource Development. Basic Books.

[5] Kalupahana, J. D. (1994). A history of Buddhist philosophy. Deilhi: Motilal Banarsidass.

[6] Siriporn Yamnilla, G. N. (June 13, 2008). The role of a religious institution in HRD: the case of Wat (temple) Panyanantaram, Thailand. Human Resource Development International.

[7] Buddha, Khuddakapāțha, Sutta Nipāta, Thripitaka.

[8] Eggland, J. G. (n.d.). Principles of Human Resource Development. Perseus Books Group.

[9] R.L.Soni, D. (2006). Life's Highest Blessings: The Maha-Mangala Sutta.

[10] Catania, A. (1986). On the difference Between Verbal and Nonverbal Behaviour. University of Maryland and Baltimore Country.

[11] Health and Safety Authority, (2011, September). Intoxicant at work, Occupational_ Health. Retrieved from http://www.hsa.ie/eng/Publications and Forms/Publications /Occupational_Health/Intoxicants_at_Work_Information_Sh eet_pdf

[12] Metcalfe, B., \& Rees, C. (2008). Global, Comparative and National HRD. Retrieved from www.ufhrd.co.uk: http://www.ufhrd.co.uk/wordpress/wp-content/uploads/2008/ 06/710metcalfe.pdf 